\title{
Monetary Policy as Equilibrium Selection
}

\author{
Gaetano Antinolfi, Costas Azariadis, and James B. Bullard
}

\begin{abstract}
Can monetary policy guide expectations toward desirable outcomes when equilibrium and welfare are sensitive to alternative, commonly held rational beliefs? This paper studies this question in an exchange economy with endogenous debt limits in which dynamic complementarities between dated debt limits support two Pareto-ranked steady states: a suboptimal, locally stable autarkic state and a constrained optimal, locally unstable trading state. The authors identify feedback policies that reverse the stability properties of the two steady states and ensure rapid convergence to the constrained optimal state. (JEL E31, E42, E58)
\end{abstract}

Federal Reserve Bank of St. Louis Review, July/August 2007, 89(4), pp. 331-41.

\section{INTRODUCTION}

\section{Overview}

ndeterminacy, or non-uniqueness, of rational expectations equilibrium has been a promi-

nent feature of monetary policy analysis since Sargent and Wallace (1975) found that passive interest rate policies cause indeterminacy in an IS-LM framework with rational expectations. Generally speaking, policy choices influence equilibrium outcomes, and passive choices can support multiple equilibria. This situation has been viewed as one to be avoided if at all possible; the prospect of the economy coordinating on the "wrong" set of self-confirming beliefs is unnecessary at best and detrimental to welfare at worst. In the standard New Keynesian model, for example, the monetary policymaker must follow a sufficiently active policy to avoid indeterminacy. "Active" means that the policy instrument cannot be held fixed, or allowed to fluctuate randomly, but instead must adjust to the state of the economy according to a specific, widely understood rule. A policy that is too passive-say, too close to a nominal interest rate peg-allows indeterminacy.

Results with this flavor depend critically on the expectations of the private sector regarding future monetary policy actions, and this has led many to describe the problem of monetary policy as one of managing or shaping expectations to rule out private sector beliefs that may send the economy toward a suboptimal course. How can policy be designed to stop this process? Can policy somehow strengthen rational beliefs in the desired inflation target and in moderate inflationary expectations?

This paper considers indeterminacy and monetary policy from a dynamic general equilibrium perspective in order to study the robustness of activist monetary policy advice, like that coming from the large literature on Taylor-type rules. ${ }^{1}$ We find these results to be quite robust. In fact, multiple Pareto-ranked dynamic equilibria turn out to occur whenever the monetary instrument

1 See the discussion in Woodford (2003) and Bullard and Mitra (2002). For a discussion of the Taylor principle, see Woodford (2001).

Gaetano Antinolfi is an associate professor of economics and Costas Azariadis is a professor of economics at Washington University in St. Louis. Azariadis is a visiting scholar and James B. Bullard is a vice president and deputy director of monetary analysis at the Federal Reserve Bank of St. Louis. The authors thank Peter Ireland for extensive comments on an earlier draft.

(C) 2007, The Federal Reserve Bank of St. Louis. Articles may be reprinted, reproduced, published, distributed, displayed, and transmitted in their entirety if copyright notice, author name(s), and full citation are included. Abstracts, synopses, and other derivative works may be made only with prior written permission of the Federal Reserve Bank of St. Louis. 
is used passively, without regard to the state of the economy. In contrast, some types of informed active policies eliminate most of the indeterminacy and force the economy onto a constrained optimal path. Our framework also begins to address interesting questions concerning the nature of the interaction between monetary policy and the smooth operation of credit markets.

\section{What We Do}

We study a dynamic general equilibrium model of pure exchange that is a simplified version of Azariadis and Kaas (2007). Following Eaton and Gersovitz (1981) and Kehoe and Levine (1993), endogenous debt limits deter default by households that cannot be forced to repay debts. These households live forever and have variable incomes. To keep the analysis tractable, we focus on an economy with just two types of agents who share a constant flow of total income. Income shares fluctuate between low and high levels in alternating periods. To smooth consumption perfectly, high-income agents could in principle lend a large enough amount to low-income agents each period to ensure that every household's share of total consumption remains constant. We show that, under certain reasonable assumptions, this first-best outcome cannot be achieved as an equilibrium with endogenous debt limits. Instead, there are two steady states: a constrained efficient outcome at a high interest rate in which credit markets work as well as possible and an inefficient autarkic outcome at a low interest rate in which credit markets break down and agents are unable to smooth consumption at all. ${ }^{2}$ A continuum of dynamical equilibria indexed by initial conditions all tend toward the suboptimal steady state.

We introduce policy into this environment. We discuss the possibility of fiscal tax-transfer schemes that would in principle work well, but which also require the policymaker to use detailed information concerning household incomes to make the correct resource realloca-

2 In the model, credit markets break down completely, but we think of this as representing poorly functioning credit markets in which the volume of borrowing and lending is less than it could be. tions. Passive monetary policy, which we think of as a constant rate of growth of the money stock, is always associated with indeterminacy and particularly poor dynamics. We then turn to active monetary policy, in which the policy instrument is adjusted in a particular way in reaction to the current state of the economy. We show that credible commitment to a certain active policy can converge to the constrained efficient outcome immediately if the policymaker reacts to the entire state of the economy and gradually if the policy rule responds only to prices. We regard this as a version of the policy advice coming from related literature on monetary policy in the face of important frictions in the economy, even though the friction in this paper is quite different. We also think this result suggests that good monetary policy is partly responsible for the smooth functioning of credit markets, a sentiment that is often stated in monetary policy circles.

\section{Recent Related Literature}

It is a typical result from the literature that models with a role for fiat money tend to have a nonmonetary steady state and an associated indeterminacy. This is true in models of overlapping generations; but the demand for money depends on beliefs in the search-theoretic monetary literature as well. ${ }^{3}$ The model here is more closely related to Bewley-type economies. ${ }^{4}$

In the New Keynesian literature, such as Woodford (2003), credit markets are complete and work perfectly, even though there are other frictions in that model. We also have complete markets, but the friction in our setting directly affects the incentives of households to lend appropriately. Thus, monetary policy in our framework improves the operation of credit markets, whereas in Woodford (2003) it has no particular effect on the operation of these markets.

\footnotetext{
3 See, for example, the discussion in Wright (2005). Other examples of indeterminacy include older Keynesian models with rational expectations, and dynamic general equilibrium structures with bubbles, complementarities, and increasing returns, such as those reviewed in Boldrin and Woodford (1990), Cooper (1999), and Benhabib and Farmer (1999).

4 See Bewley (1980) and Townsend (1980).
} 
Our results have a certain global flavor. In part that is because the model is simple enough that we can characterize the entire set of equilibria in a fairly straightforward way. Other authors have focused on a global perspective in models of monetary policy, perhaps most prominently Benhabib, Schmitt-Grohé, and Uribe (2001) and Benhabib and Eusepi (2005). They emphasize that active policies may be associated with local determinacy but global indeterminacy. In Benhabib, Schmitt-Grohé, and Uribe (2001), the second steady state (the one not associated with the inflation target of the monetary authorities) is close to the Friedman rule, whereas the second steady state in our framework is associated with high inflation. Benhabib and his collaborators emphasize how the design of policy may or may not be able to avoid too low an inflation rate relative to the target, whereas we stress how the design of monetary policy can avoid inflation rates that exceed any reasonable target. In particular, Benhabib and Eusepi (2005) show that, in a model with sticky prices, a feedback rule can eliminate global indeterminacy if the monetary instrument responds to the output gap.

\section{A NONMONETARY MODEL}

The economy we have in mind, but do not analyze here, consists of a large number of agents, possibly a continuum, with a common utility function and a large variety of income processes. Aggregate income can be thought of as constant so that we may focus on fluctuations in the distribution of income among households and on the asset trades they will conduct as they attempt to smooth consumption. Individual consumption shares will be constant if asset markets are perfect, but will necessarily fluctuate if endogenous debt limits constrain household borrowing.

To simplify matters and maintain tractability, we analyze an economy with deterministic individual incomes populated by two agents indexed by $i=0,1$. Time is discrete and denoted by $t=0,1,2, \ldots$ Each agent $i$ has preferences given by

$$
\sum_{t=0}^{\infty} \beta^{t} u\left(c_{t}^{i}\right)
$$

with $0<\beta<1$. The aggregate endowment is constant at two units, but its distribution over agents changes deterministically over time. In particular, individual endowments are periodic ${ }^{5}$; that is,

$$
\left(\omega_{t}^{0}, \omega_{t}^{1}\right)= \begin{cases}(1+\alpha, 1-\alpha) & \text { if } t=0,2, \ldots \\ (1-\alpha, 1+\alpha) & \text { if } t=1,3, \ldots,\end{cases}
$$

with $\alpha \in(0,1)$. In addition, agent zero owes an initial debt, $B=\alpha /(1+\beta)$, to agent one. This debt makes the initial wealth of the two agents identical when incomes are discounted at the common rate of time preference. In a more complicated economy, agents would be indexed by $\alpha \in(0,1)$; some individual incomes would fluctuate only a little, others would fluctuate quite a bit.

\section{Perfect Enforcement}

To fix ideas and notation, we start with a standard dynamic general equilibrium model with perfect enforcement of loan contracts. In this setting, an equilibrium is an infinite sequence $\left(c_{t}^{H}, c_{t}^{L}, R_{t}\right)$ that describes for each period $t$ consumption for the high- and low-income agents and the gross yield on loans. This sequence satisfies consumption Euler equations for each person, two intertemporal budget constraints, and market clearing. Based on our assumptions concerning the initial distribution of wealth, it is obvious that the unique equilibrium is $\left(c_{t}^{H}, C_{t}^{L}, R_{t}\right)=$ $(1,1,1 / \beta)$ for all $t$, and it is Pareto optimal. Individual consumption is a constant fraction of aggregate consumption at all times.

Commitment to repay debts is essential in achieving this allocation of resources. If borrowers can in principle default on their loan obligations at the cost of perpetual exclusion from both sides of the asset market, as suggested by Kehoe and Levine (1993), then the Pareto-optimal allocation cannot be decentralized as a competitive equilibrium with limited enforcement unless it is weakly

\footnotetext{
5 In a growing economy, individual incomes need not be negatively correlated but income shares must be. This simple deterministic endowment process is the degenerate case of a stochastic economy with two Markovian states with a zero probability of remaining in the same state. Markovian endowments with two states are a straightforward extension. The assumption of two states or dates has obvious geometric advantages, but it is not innocuous where policy is concerned. We discuss this point further in the conclusion.
} 
preferred to autarky by all agents at all times. It is easy to check that the current autarky payoff is

$$
\frac{u(1+\alpha)+\beta u(1-\alpha)}{1-\beta^{2}}
$$

for a high-income agent and

$$
\frac{u(1-\alpha)+\beta u(1+\alpha)}{1-\beta^{2}}
$$

for a low-income one. These are dominated by market participation and perpetual consumption of one unit if, and only if,

$$
u(1+\alpha)+\beta u(1-\alpha) \leq(1+\beta) u(1) .
$$

This inequality holds under conditions similar to those enumerated in Alvarez and Jermann (2000, Proposition 4.9), which require that all individuals have a strong need for consumption smoothing. In particular, inequality (5) holds if all individuals have a low intertemporal elasticity of substitution, or a low rate of time preference, or are subject to large individual income shocks. Reasonable as they might seem for an economy with two agents, these conditions are difficult to achieve in an environment with a large variety of agent types, some of whom will necessarily experience small income shocks. In what follows we assume that inequality (5) fails ${ }^{6}$ and that autarky is a state with a low implied rate of interest. Specifically, we assume

$$
u(1+\alpha)+\beta u(1-\alpha)>(1+\beta) u(1)
$$

and

$$
u^{\prime}(1+\alpha)<\beta u^{\prime}(1-\alpha) .
$$

In a more complicated model with a continuum of agents indexed by $\alpha$, inequality (7) would have to hold for some interval of $\alpha$, in particular for the highest values of $\alpha{ }^{7}$

6 If inequality (5) fails, then it is straightforward to show that highincome agents will prefer autarky to the perfect enforcement allocation for any initial distribution of debt, not just for the distribution assumed in this paper.

7 If the utility function were logarithmic, inequality (7) would require that the maximal value of $\alpha$ should exceed $(1-\beta) /(1+\beta)$, which implies that the maximal annual fluctuation in individual
These relations are shown in Figure 1, where the first-best allocation is on the diagonal and point $A$ represents autarky. An implied interest factor of unity corresponds to point $M$.

\section{Limited Enforcement}

In environments where loan contracts are enforced by perpetual exclusion of defaulters from asset markets, equilibria are defined somewhat differently from standard models. In particular, an equilibrium is an infinite sequence, $\left(c_{t}^{H}, c_{t}^{L}, R_{t}, b_{t}\right)$, where $b_{t}$ is the debt limit assigned to the low-income person at $t$. Agents maximize taking $R_{t}$ and $b_{t}$ as given, markets clear, and $b_{t}$ is the largest possible debt limit that will keep borrowers at $t$ from defaulting at date $t+1$. These limits must be binding by inequality (6), which states that the first-best allocation $\left(c_{t}^{H}, c_{t}^{L}\right)=(1,1) \forall t$ is ruled out by debt limits. In particular, (i) the consumption Euler equation holds for the highincome agent and fails for the low-income agent; that is,

$$
\beta R_{t}=\frac{u^{\prime}\left(c_{t}^{H}\right)}{u^{\prime}\left(c_{t+1}^{L}\right)}<\frac{u^{\prime}\left(c_{t}^{L}\right)}{u^{\prime}\left(c_{t+1}^{H}\right)} .
$$

(ii) Budget constraints apply, with the low-income agent borrowing at the debt limit from the highincome agent; that is,

$$
c_{t}^{H}=1+\alpha-R_{t-1} b_{t-1}-b_{t}
$$

and

$$
c_{t}^{L}=1-\alpha+R_{t-1} b_{t-1}+b_{t} .
$$

(iii) Markets clear; that is,

$$
c_{t}^{H}+C_{t}^{L}=2 .
$$

And (iv) debt limits equate the autarkic and market payoffs for a high-income consumer who is about to repay last period's debt; specifically,

$$
u\left(c_{t}^{H}\right)+\beta u\left(c_{t+1}^{L}\right)=u(1+\alpha)+\beta u(1-\alpha)
$$

for all $t$.

\footnotetext{
income should be no less than approximately 2 percent. Hence, it seems quite plausible that the first-best allocation will be prevented
} by endogenous debt limits. 


\section{Figure 1}

\section{The Fundamental Diagram}

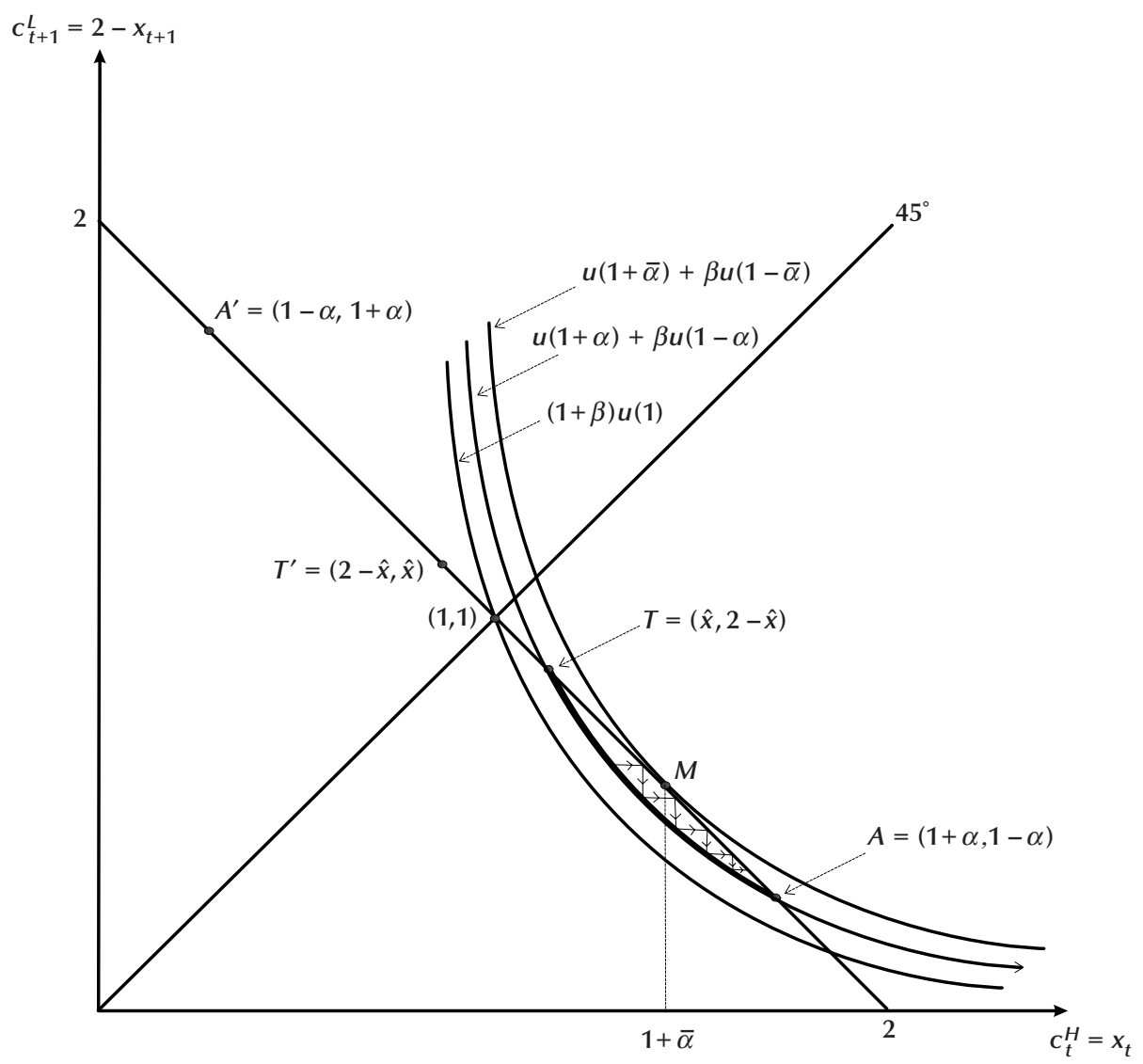

If we define $c_{t}^{H}=x_{t} \in[1,1+\alpha]$, then it is clear that equilibria are solution sequences to equation (12), that is, to

$$
u\left(x_{t}\right)+\beta u\left(2-x_{t+1}\right)=u(1+\alpha)+\beta u(1-\alpha) .
$$

These sequences are shown in Figure 1.

\section{Real Indeterminacy}

If inequalities (6) and (7) hold, Figure 1 shows that there are two steady states. This first is a stable autarkic state, $\left(c_{t}^{H}, c_{t}^{L}, R_{t}, b_{t}\right)=(1+\alpha, 1-\alpha, \bar{R}, 0)$ for all $t$, where

$$
\bar{R}=\frac{u^{\prime}(1+\alpha)}{\beta u^{\prime}(1-\alpha)}<1
$$

This state corresponds to point $A$ in Figure 1. The loan market is shut down in this state. The second is an unstable trade state, $\left(c_{t}^{H}, c_{t}^{L}, R_{t}, b_{t}\right)=$ $(\hat{x}, 2-\hat{x}, \hat{R}, \hat{b})$ for all $t$, where $\hat{x} \in(1,1+\alpha)$ is the unique solution to

$$
\begin{gathered}
u(x)+\beta u(2-x)=u(1+\alpha)+\beta u(1-\alpha), \\
\hat{R}=\frac{u^{\prime}(\hat{x})}{\beta u^{\prime}(2-\hat{x})},
\end{gathered}
$$


and

$$
\hat{b}=\frac{1+\alpha-\hat{x}}{1+\hat{R}} .
$$

This state corresponds to point $T$ in Figure 1. The loan market is active in this state. Because $T$ lies between point $M$ and the diagonal, we have

$$
\hat{R} \in(1,1 / \beta) .
$$

Because autarky is associated with an interest factor below 1, and the trading state with an interest factor above 1, it follows from Alvarez and Jermann (2000, Proposition 4.6) that the trading state is constrained optimal ${ }^{8}$ and the autarkic state is not. Individual consumption shares fluctuate less in the constrained optimal state than they do in the autarkic state.

In addition to the two steady states, there is a continuum of equilibrium sequences $\left(x_{t}\right)$ indexed on $x_{0} \in(\hat{x}, 1+\alpha)$, which converge to autarky. See again Figure 1. All of these sequences can be Pareto ranked by the initial consumption, $x_{0}$.

Equilibrium outcomes are indeterminate in this nonmonetary economy for reasons that have nothing to do with the intertemporal elasticity of substitution in consumption or the lack of gross substitutes as commonly understood. Instead, indeterminacy in this environment comes from dynamic complementarities between current and expected future debt limits. In particular, low future debt limits reduce gains from future asset trading and lower the current payoff to solvency. This, in turn, raises the incentive to default, which must be deterred by tighter debt limits now.

We conclude that the constrained optimal allocation of consumption $(\hat{x}, 2-\hat{x})$ can be achieved only if all future debt limits are expected to stay exactly at $\hat{b}$. Any other expectations will lead inevitably to autarky or to the nonexistence of equilibrium. In the remainder of the paper, we will explore whether, and how, policies can guide individual expectations in a manner that leads away from autarky and, perhaps, toward the constrained optimal allocation.

8 An allocation is constrained optimal if it satisfies the usual resource constraints, is weakly preferred to autarky by all agents at all times, and cannot be dominated by another feasible allocation.

\section{PASSIVE FISCAL AND MONETARY POLICIES}

\section{Fiscal Policy with Zero Debt Limits}

We explore here the possibility of achieving the constrained efficient allocation by a passive fiscal or monetary policy, that is, by choosing policy instruments that are invariant to the history of economic events. We start with a constant lump-sum tax, $\tau$, on the high-income agent and an equal subsidy to the low-income agent. Any tax we choose must support an equilibrium allocation that is weakly preferred to autarky by all agents at all times. This feasibility requirement excludes tax and transfer schemes that would equalize post-transfer endowments in all periods, thus implementing the first-best allocation $x_{t}=1 \forall t$ as an autarkic equilibrium. However, the policy $\tau=1+\alpha-\hat{x}$ shifts the endowment point from point $A$ to point $T$ in Figure 1 and implements the constrained optimal allocation as a unique post-transfer autarkic equilibrium at the highinterest yield, $\hat{R} \in(1,1 / \beta)$. All agents weakly prefer this outcome to the pre-transfer autarkic equilibrium at the low-interest yield, $\bar{R}<1$.

The only problem with this policy is that it relies on precise information about individual incomes, especially if there were a large variety of income types. Policy in this setting must be able to tailor individual transfers to individual incomes. Are there simpler ways to achieve desirable outcomes with a blunter policy instrument that requires less information-that is, that does not discriminate between individuals?

\section{Monetary Policy with Zero Debt Limits}

One completely anonymous instrument is fiat money printed to pay an equal lump-sum transfer to all agents. Positive lump-sum transfers flatten the distribution of current resources among households, and negative transfers skew that distribution in favor of high-income persons. This, in turn, enables monetary policy to control the real yield on money, ${ }^{9}$ which is the reciprocal

\footnotetext{
9 Identical outcomes can be achieved by changes in the stock of public debt because money and debt are perfect substitutes in our economy. We use the term "monetary policy" advisedly here
} 
of the inflation factor, along any equilibrium path. To see this, we let $M_{t}$ be the stock of money per agent, $\mu_{t}$ be the gross rate of money growth, $p_{t}$ be the price level, $\tau_{t}$ be the real value of the transfer, and $m_{t}=M_{t} / p_{t}$. Policymakers choose the sequence $\left(\mu_{t}\right)$ under the restriction that the resulting monetary equilibrium is weakly preferred to autarky by all agents at all times. We assume that agents have the option of rejecting monetary transfers and taxes in favor of autarky.

Assuming for the moment that debt limits are zero (we relax this assumption in the next subsection), budget constraints are

$$
c_{t}^{H}=1+\alpha+\tau_{t}-m_{t}^{d},
$$

where $m_{t}^{d}$ is the demand for money by highincome agents and

$$
c_{t+1}^{L}=1-\alpha+\tau_{t+1}+R_{t} m_{t}^{d},
$$

where $R_{t}=p_{t} / p_{t+1}$ is the real rate of return on money. Low-income agents are assumed to be rationed and to spend their entire money balances to raise current consumption.

Equilibrium in this economy satisfies the consumption Euler equation (8) for the highincome agent, rewritten here as

$$
u^{\prime}\left(c_{t}^{H}\right)=\beta R_{t} u^{\prime}\left(c_{t+1}^{L}\right),
$$

as well as equilibrium in the goods and money markets; that is,

$$
\begin{gathered}
c_{t}^{H}+c_{t}^{L}=2, \\
m_{t}^{d}=2 m_{t} .
\end{gathered}
$$

In addition, individual budget constraints apply; that is,

$$
c_{t}^{H} \equiv x\left(m_{t}, \mu_{t}\right)=1+\alpha-\left(1+\frac{1}{\mu_{t}}\right) m_{t} .
$$

The real return on money is

$$
R_{t}=\frac{p_{t}}{p_{t+1}}=\frac{m_{t+1}}{\mu_{t+1} m_{t}}
$$

because we expect that our results carry over to economies where debt dominates money in rate of return.
We conclude that, for a given policy sequence $\left(\mu_{t}\right)$, equilibria are bounded non-negative solution sequences $\left(m_{t}\right)$ to the nonautonomous equation,

$$
u^{\prime}\left[x\left(m_{t}, \mu_{t}\right)\right]=\beta \frac{m_{t+1}}{\mu_{t+1} m_{t}} u^{\prime}\left[2-x\left(m_{t+1}, \mu_{t+1}\right)\right] .
$$

Equilibria that converge to autarky are driven by self-confirming inflationary expectations that reduce the demand for real money balances and diminish trading between high- and low-income agents. One important drawback of passive policies is that they are unable to connect future returns on money with the current state of the economy and therefore cannot counter inflationary expectations with tighter monetary policy, that is, by lowering $\mu_{t}$.

Figure 2 shows the qualitative properties of solutions that correspond to a passive monetary policy, $\mu_{t}=\mu \in[1 / \hat{R}, 1 / \bar{R}] \forall t$, for an economy in which dated consumption goods are gross substitutes. Each policy is associated with two steady states: a stable autarkic state with $m=0$ and an unstable trading state with $m^{*}(\mu)>0$. In general, higher values of $\mu$ correspond to lower steadystate returns on money and to a lower demand for money, $m^{*}(\mu)$. For example, $\mu=1 / \hat{R} \in(\beta, 1)$ supports the constrained optimal trading state, $c_{t}^{H}=\hat{x}$, for all $t$ by raising the value of real balances to

$$
m^{*}(1 / \hat{R})=\frac{1+\alpha-\hat{x}}{1+\hat{R}} .
$$

This value of $\mu$, which involves a mild deflation at the steady state of an economy with zero income growth, is the lowest feasible rate of growth consistent with all agents preferring monetary equilibrium to autarky at all times. The Friedman rule, $\mu=\beta$, which would support the first-best allocation $c_{t}^{H}=1$ for all $t$ is simply not feasible: It imposes too large a tax on high-income agents, causing them to choose autarky over the use of money. As we raise the value of $\mu$ above $1 / \hat{R}$, the amount of trading between the two groups of agents shrinks, vanishing at $\mu=1 / \hat{R}$; here the steady-state return on money is equal to the autarkic rate of return.

Figure 2 reveals that feasible passive policies cannot overcome the indeterminacy problem of 
Figure 2

\section{Passive Policies}

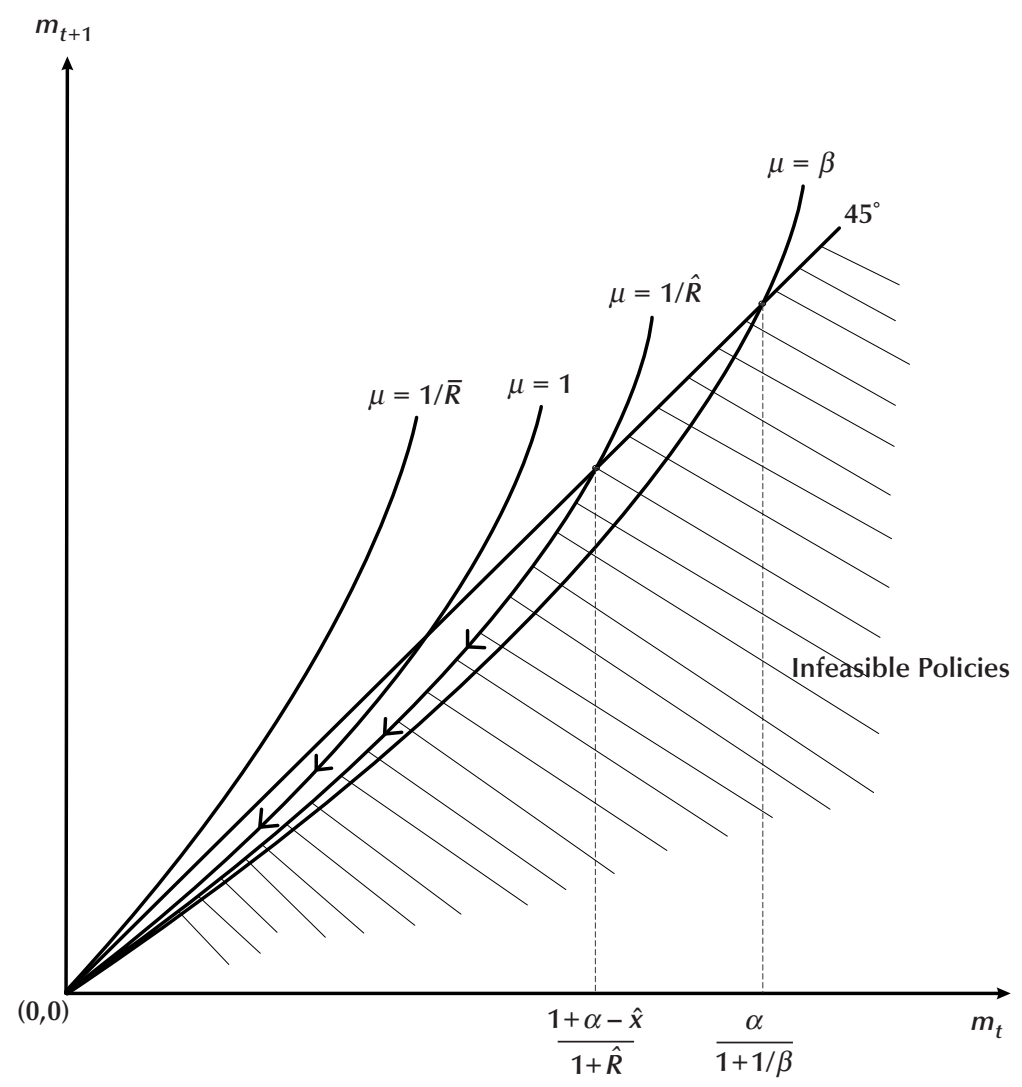

self-fulfilling inflationary expectations that leads to reduced trade among households. To solve this problem, policy should connect the current state of the economy with future returns on money, that is, with expectations of future inflation. We explore active feedback policies in the "Active Monetary Policy" section.

\section{Monetary Policy with Positive Debt Limits}

Positive debt constraints add nothing essential to the equilibria described in the previous subsection because holdings of private debt are a perfect substitute for balances of fiat money. A high-income individual has the same payoff when trading loans as he would if he held only money. Loan default does not hurt the trading opportunities of any individual.

If debt limits are a positive sequence $\left(b_{t}\right)$, the budget constraint for a high-income individual,

$$
\begin{aligned}
c_{t}^{H} & =1+\alpha-\left(1+\frac{1}{\mu_{t}}\right) m_{t}-R_{t-1} b_{t-1}-b_{t} \\
& =1+\alpha-\left(m_{t}+b_{t}\right)-R_{t-1}\left(m_{t-1}+b_{t-1}\right),
\end{aligned}
$$

indicates that only the size of the asset portfolio matters for individual plans, not its division into fiat money and debt. Money displaces private loans at a one-to-one rate. 


\section{ACTIVE MONETARY POLICY}

Suppose next that monetary policy can control directly the real yield on money balances in a manner that depends on the entire state of the economy. We index that state by $\left(x_{t}, R_{t}\right)$, where $x_{t}$ is twice the consumption share of the high-income agent and $R_{t}$ is the real yield on money and debt. Equivalently, we may index the state by $\left(m_{t}, R_{t}\right)$, where $m_{t}$ is real balances per capita. Then we write the policy function as

$$
R_{t+1}=f\left(x_{t}, R_{t}\right) .
$$

The arbitrary function $f$ maps the product space $[1,1+\alpha] \times[\bar{R}, \hat{R}]$ into $[\bar{R}, \hat{R}]$. It should be consistent with autarky (because autarky is an equilibrium whenever households refuse to accept fiat money in exchange for goods) and with the constrained optimal state $(\hat{x}, \hat{R})$ (because this state is a reasonable target for a benevolent policymaker). This requires that

$$
\begin{gathered}
\bar{R}=f(1+\alpha, \bar{R}), \\
\hat{R}=f(\hat{x}, \hat{R}) .
\end{gathered}
$$

An example of this type of policy is

$$
f(x, R)=\left\{\begin{array}{cl}
\bar{R} \quad \text { if }(x, R)=(1+\alpha, \bar{R}) \\
\frac{2-\hat{x}}{\beta(2-\beta R x)} \text { otherwise. }
\end{array}\right.
$$

Given the policy $f$, an equilibrium is a sequence $\left(x_{t}, R_{t}\right)$ that satisfies (29), plus the consumption Euler equation of the high-income agent, rewritten here as

$$
u^{\prime}\left(x_{t}\right)=\beta R_{t} u^{\prime}\left(2-x_{t+1}\right) .
$$

By construction, the dynamical system (29) and (33) has two steady states, $(x, R)=(1+\alpha, \bar{R})$ and $(\hat{x}, \hat{R})$. A sensible policy $f(\cdot)$ ensures that equilibria starting at any point $\left(x_{0}, R_{0}\right)$ move away from the suboptimal autarkic state $(1+\alpha, \bar{R})$ and converge rapidly to the constrained optimal state $(\hat{x}, \hat{R})$.

We do not attempt a global characterization of policies that achieve this objective for an arbitrary utility function $u(\cdot)$. We instead confine ourselves to exploring the properties of such policies for a logarithmic utility function in the neighborhood of each steady state. In this class of economies, equilibria satisfy

$$
\begin{gathered}
x_{t+1}=2-\beta R_{t} x_{t}, \\
R_{t+1}=f\left(x_{t}, R_{t}\right) .
\end{gathered}
$$

All we need do is study the characteristic polynomial $p(\lambda)$ in the neighborhood of any steady state $(x, R)$. That polynomial is

$$
g(\lambda)=\lambda^{2}+\beta R\left(\beta R-\varepsilon_{R}\right) \lambda+\beta R\left(\varepsilon_{x}-\varepsilon_{R}\right)
$$

where $\varepsilon_{X}$ and $\varepsilon_{R}$ are partial elasticities of the policy function $f$ with respect to $x$ and $R$, and $\beta R<1$ at each steady state.

Desirable policies, as we have described them, should turn the constrained optimal steady state into an attractor, or sink, and the suboptimal state into a source. The eigenvalues, or roots of the polynomial $g(\lambda)$, should be inside the unit circle at $(x, R)=(\hat{x}, \hat{R})$ and outside the unit circle at $(\bar{x}, \bar{R})$. One way to choose is to focus on functions $f$ that raise future real yields whenever households with currently high incomes consume "too much" (relative to the efficient outcome, $\hat{x}$ ) and demand "too little" money.

It is easy to check whether the policy function in equation (32) has exactly this property, which would furthermore guarantee immediate convergence to the constrained efficient state $(\hat{x}, \hat{R})$ from any initial condition other than autarky. Under this policy, the dynamical system consisting of equations (34) and (35) has a double real eigenvalue with modulus zero at $(\hat{x}, \hat{R})$.

Exactly what does the monetary authority have to do to control the real rate of interest in the manner specified by the policy function in (32)? This can be answered with a logarithmic utility function: Combine the budget constraint (24) with the Euler equation (26) to obtain an expression that connects monetary policy at date $t+1$ with monetary policy at $t$ and with the state of the economy at $t$. In particular, we find that

$$
1+\mu_{t+1}=\frac{1+\mu_{t}}{\mu_{t}} \frac{\left(\beta x_{t}-\frac{1-\alpha}{R_{t}}\right)}{\left(1+\alpha-x_{t}\right)} .
$$


We conclude that monetary policy tightens ( $\mu_{t+1}$ falls) subsequent to a rise in the rate of inflation and a drop in the rate of return on money. Equation (37) says that the tightening appears to be substantial. For example, if $\alpha$ is small relative to unity, $\beta$ is about 0.95 , and the ratio of money to income is about 1:7; then, each additional 1 percentage point of inflation near the constrained efficient steady state causes the money growth rate to drop by about 7 percentage points. To see this, we calculate the response of the money growth rate to changes to the past inflation rate from equations (37) and (24) and obtain

$$
\frac{d \mu_{t+1}}{d\left(1 / R_{t}\right)}=\frac{1-\alpha}{m_{t}}
$$

Then, we set $\alpha=0$ and $m_{t}=1 / 7$.

This is the sort of strongly reactive policy that guides inflationary expectations to just the level needed to support the constrained efficient outcome. In a similar but not quite as effective way, outcomes can be achieved if the policy rule simply maps current inflation into future inflation, ignoring current quantities such as $x_{t}$ and $m_{t}$. Specifically, if we employ the rule

$$
R_{t+1}=\phi\left(R_{t}\right),
$$

where $\phi$ maps the interval $[\bar{R}, \hat{R}]$ into itself, then the dynamical system consisting of equations (34) and (38) has two real eigenvalues, $-\beta R$ and $\phi^{\prime}(R)$, at any steady state $(x, R)$. Recall that $\beta R \in(0,1)$ at both $\bar{R}$ and $\hat{R}$.

Therefore, any policy rule such that $\left|\phi^{\prime}(\bar{R})\right|>1$ and $\left|\phi^{\prime}(\hat{R})\right|<1$ will convert the autarkic state $A$ into a saddle and the trading state $T$ into a sink. For most initial conditions $\left(x_{0}, R_{0}\right)$, monetary policy leads the economy to converge asymptotically, but not immediately, to the constrained efficient state.

\section{CONCLUSIONS AND EXTENSIONS}

This paper provides general equilibrium examples of how active monetary policy can be used to select a desirable outcome in economies where passive policies are associated with many Pareto-ranked dynamic equilibria.
In our setting, monetary policy works directly on rational beliefs about future values of the inflation rate, debt limits, and other financial variables. It does so by committing to a feedback rule that connects current financial conditions with future values of the policy instrument and, in particular, to a shared belief that asset returns will improve substantially when the volume of asset trading falls below what is consistent with an efficient allocation of resources.

When viewed as an exercise in equilibrium selection, monetary policy is an attempt to foster expectations that lead to socially desirable states of the economy as rapidly as possible. This attempt is completely successful in our simple setting where money is a perfect substitute for private debt, that is, a store of value for two agents trading in complete, albeit imperfect, asset markets. Efficiency in this setting is achieved when the volume of loans is as large as capital-market imperfections will allow. If that volume is less than it should be, properly valued money can act as a substitute for private loans. The job of the central bank is to defend the correct value of money by connecting expectations of future inflation with current economic conditions and intervening aggressively to pin inflation expectations to the right value.

We are not sure that a blunt policy instrument such as anonymous monetary policy will be as successful in selecting constrained optimal outcomes in a richer environment with many agents and uncertainty. In particular, if money and debt are imperfect substitutes because the former has a liquidity advantage over the latter, then monetary policy has implications for debt limits and for the participation of households in financial markets. In addition, policy choices may not be conditioned on the entire state of the economy if that state includes detailed information about individual incomes and trading plans. In that case, the policymaker may have to settle for something less than constrained efficiency, as in Benhabib and Eusepi (2005). These implications need to be carefully explored before we can design monetary rules with any degree of confidence. 


\section{REFERENCES}

Alvarez, Fernando and Jermann, Urban J. "Efficiency, Equilibrium, and Asset Pricing with Risk of Default." Econometrica, July 2000, 68(4), pp. 775-97.

Azariadis, Costas and Kaas, Leo. "Asset Price Fluctuations Without Aggregate Shocks.” Journal of Economic Theory, 2007 (forthcoming).

Benhabib, Jess and Eusepi, Stefano. "The Design of Monetary and Fiscal Policy: A Global Perspective." Journal of Economic Theory, July 2005, 123(1), pp. 40-73.

Benhabib, Jess and Farmer, Roger E.A. "Indeterminacy and Sunspots in Macroeconomics," in J. Taylor and M. Woodford, eds., Handbook of Macroeconomics. Volume 1A. Amsterdam: North-Holland, 1999, pp. 387-448.

Benhabib, Jess; Schmitt-Grohé, Stephanie and Uribe, Martin. "The Perils of Taylor Rules." Journal of Economic Theory, January/February 2001, 96(1-2), pp. 40-69.

Bewley, Truman. "The Optimum Quantity of Money," in J. Kareken and N. Wallace, eds., Models of Monetary Economies. Federal Reserve Bank of Minneapolis, 1980.

Boldrin, Michele and Woodford, Michael. "Equilibrium Models Displaying Endogenous Fluctuations and Chaos: A Survey." Journal of Monetary Economics, March 1990, 25(2), pp. 189-222.

Bullard, James B. and Mitra, Kaushik. "Learning about Monetary Policy Rules.” Journal of Monetary Economics, September 2002, 49(6), pp. 1105-29.
Cooper, Russel W. Coordination Games: Complementarities and Macroeconomics. Cambridge, MA: MIT Press, 1999.

Eaton, Jonathan and Gersovitz, Mark. "Debt with Potential Repudiation: Theoretical and Empirical Analysis." Review of Economic Studies, April 1981, 48(2), pp. 289-309.

Kehoe, Timothy J. and Levine, David K. "DebtConstrained Asset Markets." Review of Economic Studies, October 1993, 60(4), pp. 865-88.

Sargent, Thomas J. and Wallace, Neil. "Rational Expectations, the Optimal Monetary Instrument, and the Optimal Money Supply Rule." Journal of Political Economy, April 1975, 83(2), pp. 241-54.

Townsend, Robert M. "Models of Money with Spatially Separated Agents," in J. Kareken and N. Wallace, eds., Models of Monetary Economies. Federal Reserve Bank of Minneapolis, 1980.

Woodford, Michael. "The Taylor Rule and Optimal Monetary Policy." American Economic Review, May 2001, 91(2), pp. 232-37.

Woodford, Michael. Interest and Prices: Foundations of a Theory of Monetary Policy. Princeton, NJ: Princeton University Press, 2003.

Wright, Randall. "Introduction to 'Models of Monetary Economies II: The Next Generation.”' International Economic Review, May 2005, 46(2), pp. 305-16. 
